\title{
並行流熱交換器における共役グレツ問題の解析解
}

\section{An analytical solution to conjugated Graetz problems in parallel flow heat exchangers}

\author{
O正 千葉良一（宮城高専） 正 泉正明（石巻専修大） 正 菅野良弘（岩手大）
}

\begin{abstract}
Ryoichi CHIBA, Miyagi National College of Technology, Nodayama48, Medeshimasiote, Natori Masaaki IZUMI, Ishinomaki Sensyu University, Shinmito1, Minamisakai, Ishinomaki Yoshihiro SUGANO, Iwate University, 4-3-5, Ueda, Morioka
\end{abstract}

Key Words: Heat Transfer, Forced Convection, Heat Exchanger, Non-Newtonian Fluid, Analytical Solution

\section{1. 緒言}

近年の都市化に伴い，産業分野のみならず民生分野におい ても設備機器スペースを効率的に運用することが要望され ており，それらの中に組み込まれる熱交換器にも小型化が求 められている.ところで小型熱交換器では, 機器内部を流れ る流体の流路長が比較的短く, 加熱流体および受熱流体の温 度場が十分発達しない場合があるため, 熱貫流率を全伝熱面 にわたり一定と仮定して取り扱う従来の設計法は適用でき ない。このように熱貫流率が空間的に変化する場合，その熱 交換器の性能評価をより正確に行うには, 加熱流体と受熱流 体間の連成強制対流熱伝達問題，いわゆる共役Graetz問題を 解く必要がある. しかし, この問題は一般に半数值的解法 ${ }^{(1)}$ により解かれており，これまでに報告された解析解は，境界 層理論と漸近展開法を用いた近似解 (2)のみである.

そこで本研究では, 流路が平行平板に挟まれた領域である 並行流熱交換器に対する「流体-流体 共役Graetz問題」を,

一種の積分変換法に相当するVodickaの手法 ${ }^{(3)}$ を用いて数学 的に解き, 流れ方向に変化する流体温度の解析解を陽な形式 で導出する. なおう, 本研究ではぺクレ数が十分大きい範囲を 対象ししているので，流れ方向への熱伝導は無視している. 本手法を用いる限り平板間を流れる流体の速度分布形には 解析上制限がないので，一例として，加熱流体および受熱流 体はともにべキ乗則に従う非ニュートン流体であるとした. 数值計算結果より, 流体の熱伝導率比, 流路断面積比および ペクレ数比が流体の温度分布と流体間の交換熱量に及ぼす 影響を考察した。

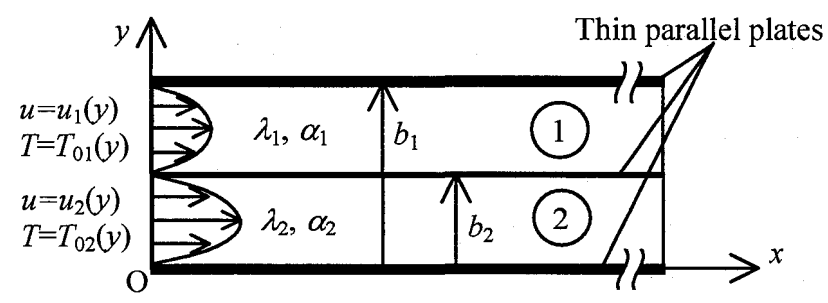

Fig.1 Physical model and coordinate system for the parallel flow heat exchanger

\section{2. 解 析}

2-1 解析モデルと定式化 解析モデルを図 1 に示す. 平 行平板間 (以降, 流路と記す) に, 発達した速度分布 $u_{1}(y), u_{2}(y)$ をもった流体(1)と流体(2)が流入している. 流路入口における 流体温度はそれぞれ $T_{01}(y), T_{02}(y)$ である. $y=0, b_{1}$ の面は断熱 されており， $y=b_{2}$ の面を通して両流体間で熱交換が行われ る.また，以下の仮定を導入する．(i)物性值は温度によらず 一定. (ii)平板の熱抵抗は無視できる. (iii)流れ方向の熱伝導 は無視できる. (iv)流れは常に層流である. (v)自然対流は生 じない. (vi)粘性による発熱は無視する.
この場合，定常時の熱平衡は式(1)で表される.

$$
u_{m}(y) \frac{\partial T_{m}}{\partial x}=\alpha_{m} \frac{\partial^{2} T_{m}(x, y)}{\partial y^{2}}, m=1,2
$$

発達した速度場における速度分布は, 無次元座標: $\eta=y / b_{1}$, 流路断面積比: $B=b_{2} / b_{1}$ を導入すれば式(2),(3)で与えられる.

$$
\begin{gathered}
u_{1}(y)=u_{a 1} \frac{2 v_{1}+1}{v_{1}+1}\left(\frac{2}{1-B}\right)^{\frac{1+v_{1}}{v_{1}}}\left[\left(\frac{1-B}{2}\right)^{\frac{1+v_{1}}{v_{1}}}-\left|\frac{2 \eta-B-1}{2}\right|^{\frac{1+v_{1}}{v_{1}}}\right] \\
u_{2}(y)=u_{a 2} \frac{2 v_{2}+1}{v_{2}+1}\left(\frac{2}{B}\right)^{\frac{1+v_{2}}{v_{2}}}\left[\left(\frac{B}{2}\right)^{\frac{1+v_{2}}{v_{2}}}-\left|\eta-\frac{B}{2}\right|^{\frac{1+v_{2}}{v_{2}}}\right]
\end{gathered}
$$

ここで, $v_{m}(m=1,2)$ はべキ乗則モデルインデックスと呼ばれ, $v_{m}<1$ なら擬塑性流体を, $v_{m}>1$ ならダイラタント流体を表し, $v_{m}=1$ の場合はニュートン流体に相当する.

境界条件と $y=b_{2}$ の面での連続条件は次式のとおりである.

$$
\begin{aligned}
& T_{m}(0, y)=T_{0 m}(y), m=1,2 \\
& \frac{\partial T_{2}(x, 0)}{\partial y}=\frac{\partial T_{1}\left(x, b_{1}\right)}{\partial y}=0 \\
& \lambda_{1} \frac{\partial T_{1}\left(x, b_{2}\right)}{\partial y}=\lambda_{2} \frac{\partial T_{2}\left(x, b_{2}\right)}{\partial y}, T_{1}\left(x, b_{2}\right)=T_{2}\left(x, b_{2}\right)
\end{aligned}
$$

解析結果の一般性を考慮して, 式(1), (4)〜 (6)を無次元表記 すると，式(7)〜 (10)が導かれる.

$$
\begin{aligned}
& U_{m}(\eta)\left[\overline{P e} \frac{(1-B)}{B}\right]^{m-1} \frac{\partial \theta_{m}}{\partial \xi}=\frac{\partial^{2} \theta_{m}}{\partial \eta^{2}}, m=1,2 \\
& \theta_{m}(0, \eta)=\theta_{0 m}(\eta), m=1,2 \\
& \frac{\partial \theta_{2}(\xi, 0)}{\partial \eta}=\frac{\partial \theta_{1}(\xi, 1)}{\partial \eta}=0 \\
& \frac{\partial \theta_{1}(\xi, B)}{\partial \eta}=\bar{\lambda} \frac{\partial \theta_{2}(\xi, B)}{\partial \eta}, \theta_{1}(\xi, B)=\theta_{2}(\xi, B)
\end{aligned}
$$

ただし, 無次元流速: $U_{1}(\eta)=u_{1}(\eta) / u_{a 1}, U_{2}(\eta)=u_{2}(\eta) / u_{a 2}$, ペ クレ数比: $\overline{P e}=\alpha_{1} u_{a 2} b_{2} /\left[\alpha_{2} u_{a 1}\left(b_{1}-b_{2}\right)\right]$, 熱伝導率比: $\bar{\lambda}=\lambda_{2} / \lambda_{1}$, 無次元温度: $\theta_{m}=\left(T_{m}-T_{\mathrm{s}}\right) /\left(T_{01 \mathrm{~b}}-T_{\mathrm{s}}\right)$, 熱拡散率: $\alpha_{1}, \alpha_{2}$, 参照温度: $T_{\mathrm{s}}$, 平均流速: $u_{\mathrm{a} 1}, u_{\mathrm{a} 2}$, 流体(1)の入口でのバルク温度: $T_{01 \mathrm{~b}}$, 無 次元流れ方向座標: $\xi=x \alpha_{1} /\left(b_{1}^{2} u_{a 1}\right)$ である.

式(7)は変数係数P.D.E.であり, 厳密解を得ることは非常に 困難である. そこで，各流路内を $y$ 方向 $(\eta$ 方向 $)$ にそれぞれ $n_{1}$, $n_{2}$ 領域に分割し, 各領域で $U_{m}(\eta)$ を相異なる一定值 $U_{i}^{*}$ と近似 すれば，第䕘域 $\left(i=1,2, \ldots, n_{1}+n_{2}\right)$ における熱平衡式が式(11) のように得られる。.なお，これ以降の流添え字は流体番号 ではなく，仮想的に分割された領域番号を意味する. 
$K_{i} \frac{\partial \theta_{i}}{\partial \xi}=\frac{\partial^{2} \theta_{i}}{\partial \eta^{2}}$

ただし， $K_{i}=\left\{\begin{array}{cc}U_{i}^{*} \overline{P e}(1-B) / B & 1 \leq i \leq n_{2} \\ U_{i}^{*} & n_{2}+1 \leq i \leq n_{1}+n_{2}\end{array}\right.$

仮想界面における連続条件と境界条件は次式で表される。

$$
\begin{aligned}
& \theta_{i}\left(\xi, \eta_{i}\right)=\theta_{i+1}\left(\xi, \eta_{i}\right) \\
& \frac{\lambda_{i}}{\lambda_{i+1}} \frac{\partial \theta_{i}\left(\xi, \eta_{i}\right)}{\partial \eta}=\frac{\partial \theta_{i+1}\left(\xi, \eta_{i}\right)}{\partial \eta} \\
& \theta_{i}(0, \eta)=\theta_{0 m}(\eta), 1 \leqq i \leqq n_{2} ; m \\
& \frac{\partial \theta_{1}(\xi, 0)}{\partial \eta}=\frac{\partial \theta_{\left(n_{1}+n_{2}\right)}(\xi, 1)}{\partial \eta}=0
\end{aligned}
$$$$
\theta_{i}(0, \eta)=\theta_{0 m}(\eta), 1 \leqq i \leqq n_{2} ; m=2, n_{2}+1 \leqq i \leqq n_{1}+n_{2} ; m=1 \text { (14) }
$$

2-2 Vodickaの手法による解析解の導出 式(11)〜(15)の 解を式(16)の形に分離する.

$$
\theta_{i}(\xi, \eta)=\sum_{l=1}^{\infty} \phi_{l}(\xi) X_{i l}(\eta)+\theta_{\mathrm{av}}
$$

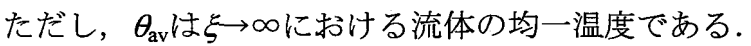

固有関数 $X_{i}(\eta)$ は式(17)で与えられる.

$$
X_{i l}(\eta)=A_{i l} \cos \left(\sqrt{K_{i}} \gamma_{l} \eta\right)+B_{i l} \sin \left(\sqrt{K_{i}} \gamma_{l} \eta\right)
$$

未知係数 $A_{i l}, B_{i l}$ は式(12)，(13)，(15)より決定される. また，固 有值 $\gamma_{l}$ は $A_{i l}, B_{i l}$ が 0 以外の解を持つための条件から決定され, 式(18)で表される超越方程式の正根として求められる.

$$
\mathbf{G}_{e 1} \cdot \mathbf{E}_{e 1} \cdot \mathbf{E}_{e 2} \cdots \mathbf{E}_{e\left(n_{1}+n_{2}-1\right)} \cdot \mathbf{a}_{e\left(n_{1}+n_{2}\right)}=0
$$

ここで,

$$
\begin{gathered}
\mathbf{G}_{e \mathrm{1}}=\left[\begin{array}{ll}
0 & \sqrt{K_{1}} \gamma_{l}
\end{array}\right], \mathbf{E}_{e i}=\mathbf{C}_{e i}^{-1} \mathbf{D}_{e(i+1)}, \\
\mathbf{C}_{e i}=\left[\begin{array}{cc}
\cos \left(\sqrt{K_{i}} \gamma_{l} \eta_{i}\right) & \sin \left(\sqrt{K_{i}} \gamma_{l} \eta_{i}\right) \\
-\lambda_{i} / \lambda_{i+1} \sqrt{K_{i}} \gamma_{l} \sin \left(\sqrt{K_{i}} \gamma_{l} \eta_{i}\right) & \lambda_{i} / \lambda_{i+1} \sqrt{K_{i}} \gamma_{l} \cos \left(\sqrt{K_{i}} \gamma_{l} \eta_{i}\right)
\end{array}\right], \\
\mathbf{D}_{e(i+1)}=\left[\begin{array}{cc}
\cos \left(\sqrt{K_{i+1}} \gamma_{l} \eta_{i}\right) & \sin \left(\sqrt{K_{i+1}} \gamma_{l} \eta_{i}\right) \\
-\sqrt{K_{i+1}} \gamma_{l} \sin \left(\sqrt{K_{i+1}} \gamma_{l} \eta_{i}\right) & \sqrt{K_{i+1}} \gamma_{l} \cos \left(\sqrt{K_{i+1}} \gamma_{l} \eta_{i}\right)
\end{array}\right], \\
\mathbf{a}_{e\left(n_{1}+n_{2}\right)}=\left[\begin{array}{lll}
1 & \tan \left(\sqrt{K_{n_{1}+n_{2}}} \gamma_{l}\right)
\end{array}\right]^{\mathrm{T}}
\end{gathered}
$$

式(19)中の T は転置行列記号である. 式(14)に式(16)を代入し $\tau$, 次の条件式を得る.

$$
G(\eta)=\sum_{l=1}^{\infty} \phi_{l}(0) X_{i l}(\eta)=\theta_{0 m}(\eta)-\theta_{\mathrm{av}}
$$

さて，式(17)で与えられる固有関数 $X_{i l}(\eta)$ は，不連続な重み 関数に対して式(21)の直交関係を有する。

$$
\sum_{i=1}^{n_{1}+n_{2}} K_{i} \eta_{\eta_{i-1}}^{n_{i}} X_{i l}(\eta) X_{i k}(\eta) \mathrm{d} \eta=\left\{\begin{array}{cc}
\text { const. } & (l=k) \\
0 & (l \neq k)
\end{array}\right.
$$

この場合， $G(\eta)$ は $X_{i}(\eta)$ により式(22)のように級数展開できる.

$$
G(\eta)=\sum_{l=1}^{\infty} g_{l} X_{i l}(\eta)
$$

ただし，

$$
g_{l}=\sum_{i=1}^{n_{1}+n_{2}} K_{i} \eta_{\eta_{i-1}}^{n_{i}} G(\eta) X_{i l}(\eta) \mathrm{d} \eta / \sum_{i=1}^{n_{1}+n_{2}} K_{i} \int_{\eta_{i-1}}^{n_{i}}\left[X_{i l}(\eta)\right]^{2} \mathrm{~d} \eta
$$

式(16)を式(11)に代入し，式(17)を考慮すれば，式(24)で表さ れる $\phi(\xi)$ に関する1階線形常微分方程式が得られる.

$$
\frac{\mathrm{d} \phi_{l}}{\mathrm{~d} \xi}+\gamma_{l}^{2} \phi_{l}=0
$$

式(20)，(22)より得られる $\phi_{l}(0)=g_{l}$ を用いて式(24)を解けば, $\phi_{(}(\xi)$ は式(25)で表現される.

$$
\phi_{l}(\xi)=g_{l} \exp \left(-\gamma_{l}^{2} \xi\right)
$$

したがって, 第䕘域における温度関数 $\theta_{i}(\xi, \eta)$ は次式となる.

$\theta_{i}(\xi, \eta)=\sum_{l=1}^{\infty} g_{l} e^{-\gamma_{l}^{2} \xi}\left[A_{i l} \cos \left(\sqrt{K_{i}} \gamma_{l} \eta\right)+B_{i l} \sin \left(\sqrt{K_{i}} \gamma_{l} \eta\right)\right]$

\section{3. 数値計算結果および考察}

数值計算の一例として, 流路断面積が等しい平行平板熱交 換器に, 相異なる一定温度のニュートン流体が流入している 問題, 即ち $\theta_{01}(\eta)=1, \theta_{02}(\eta)=0, B=0.5$ かつ $v_{1}=v_{2}=1$ の場合 を考察する. 本計算では, 各流路の $\eta$ 方向への分割数として $n_{1}=n_{2}=20$ を採用した. なお, 領域分割数を 20 以上にとれば, 工学的に十分な計算精度が得られることを確認している ${ }^{(4)}$.

図 2 に流路断面に㧈ける温度分布の流れ方向一の変化を示 す．図2(a)は同一流体間での熱交換の場合であり，図2(b)は 加熱および受熱流体にそれぞれ空気と水を想定した場合で ある. 同一流体の場合， $\overline{P e}>1$ だと加熱流体側の温度変化が

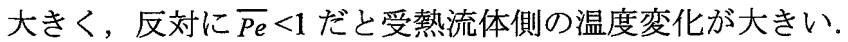

図3は流体(1)のバルク温度の流れ方向への変化を示してお り，比較のために，従来のように平均熱貫流率と対数平均温 度差を用いて評価したものも図中に示している. 本研究では 平均熱貫流率の算出にNickolay ( $^{(5)}$ の式を用いた。図より， 従来の方法では加熱流体のバルク温度が過小に評価されて いることがわかる.また，最終的な温度への収束の程度が両 者間で異なっており, 収束に至る年值に約 0.6 の開きがある.

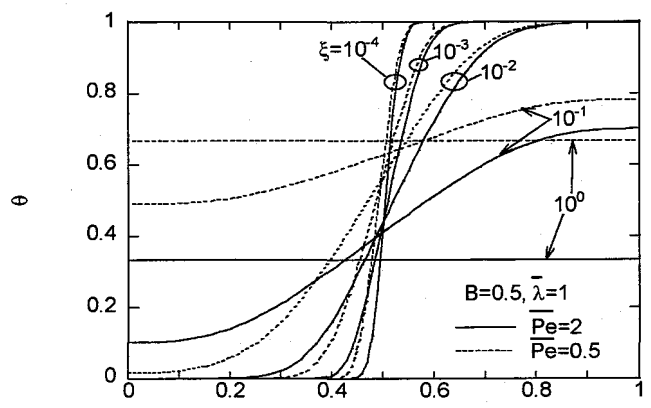

(a)

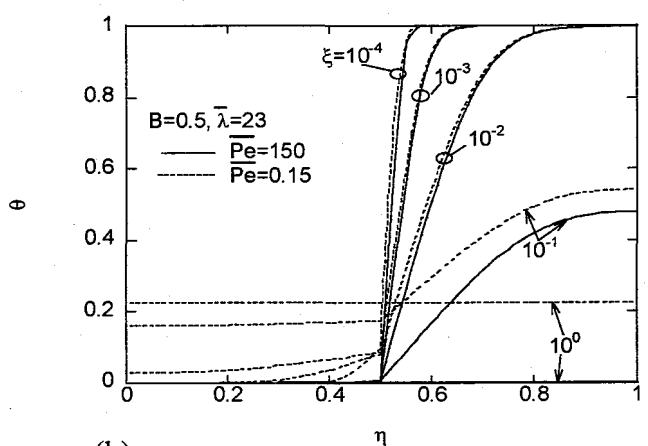

(b)

Fig.2 Spatial evolution of the temperature fields

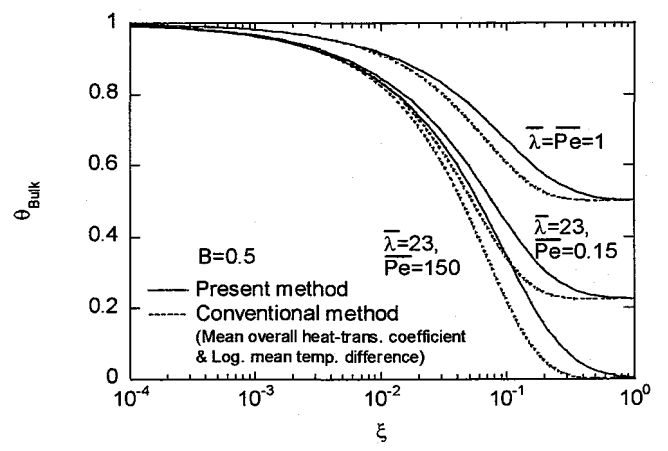

Fig.3 Bulk temperature of fluid(1) in thermal entry region of a parallel flow heat exchanger

\section{文献}

(1) E. Nogueira et al., Warme-und Stoffubertragung, 25, (1990), 361.

(2) P. Plaschko, Archive of Applied Mech., 70, (2000), 597.

(3) V. Vodicka, Mathematische Nachrichten, 14-1, (1955), 47

(4)千葉，泉，菅野，関東支部茨城講演会論文集，(2005-9), 7 .

(5) M. Nickolay et al., Int. J. Heat Mass Trans., 45, (2002), 3263. 